\title{
NOTES ON THE ESTIMATION OF CAFFEIN.
}

BY W. A. PECKNER.

Received Seprember 2,1896 .

GOME time ago Gomberg published a method for the estima$\checkmark$ tion of caffein, by means of Wagner's reagent, ${ }^{\prime}$ wherein appear certain statements from which is to be inferred the superiority of this method over such where the caffein is shaken out of an aqueous solution by means of chloroform, and which, if true, would show that most methods now in use, give low results since but an imperfect separation of caffein is attained. Thus Spencer ${ }^{2}$ is said to have demonstrated the difficulty with which the alkaloid is abstracted from watery solutions, he directing that at least seren portions of chloroform be used for this purpose, but offering no proof of the necessity for this departure from the usual direction of shaking out the liquid with three or four portions of the solvent. Spencer is at variance with Allen, ${ }^{3}$ who investigated this matter and found that from a solution, slightly acidulated with sulphuric acid, one treatment with chloroform removed seventy to eighty-five per cent. of the amount present, while four usually effected complete extraction, especially if toward the end the solution is rendered faintly alkaline.

This agrees well with the results of my own experiments, where anhydrous caffein, in quantities from one-tenth to fourtenths gram, dissolved in fifty cc. one per cent. sulphuric acid, was shaken successively with twenty-five, ten and ten cc. chloroform, the united chloroform solution evaporated at a gentle heat and the residue dried over sulphuric acid to constant weight. In each case the solution was shaken with a further quantity of ten cc. chloroform and the weight of the caffein so extracted ascertained as before.

$\begin{array}{cccc}\text { Caffein } & \begin{array}{c}\text { Residue from fist, second } \\ \text { and third extraction. } \\ \text { Gram. }\end{array} & \begin{array}{c}\text { Residue from } \\ \text { fourth extraction. }\end{array} & \begin{array}{c}\text { Total per cent. } \\ \text { recovered. }\end{array} \\ 0.1285 & 0.1277 & 0.0004 & 99.69 \\ 0.1852 & 0.1820 & 0.0026 & 99.67 \\ 0.1988 & 0.1980 & 0.0002 & 99.69 \\ 0.2011 & 0.1977 & 0.0025 & 99.55 \\ 0.2559 & 0.2552 & 0.0005 & 99.92 \\ 0.4416 & 0.4355 & 0.0043 & 99.58\end{array}$

1 This Journat, 18, $33 \mathrm{I}$.

2J. Anal. Chem., 4, 390.

3 Com. Org. Anal, 3 , lart II, 485. 
This shows that the extraction of caffein from an aqueous solution presents no difficulties since, even when the solution is quite acid, practically the entire amount is obtained when four portions of chloroform are used; while, even if the fourth be omitted the results will be sufficiently correct for most purposes.

In the article referred to we are also told, although it is usually stated caffein may be shaken out of an acid solution, since its salts are broken up by water, that this is but relatively true; as a proof thereof the following is offered:

"I.0085 grams of caffein were dissolved in sixty cc. of sulphuric acid (I.IO), and this solution was repeatedly shaken with chloroform, twenty-five $\mathrm{cc}$. at a time:

Ten consecutive portions of chloroform gave a total of 0.35 I4 gram caffein. Three additional

Three more " made " " " 0.5034

Since the degree of dissociation of caffein salts is inversely proportional to the acid strength of the solution, it is to be expected that it will be extremely difficult to shake out the alkaloid from a solution containing so great a quantity of free acid; but while at times it may be advantageous to extract caffein from a solution having an acid reaction, in no instance would there seem need of a sufficient amount to render the method inapplicable; further, according to Knox and Prescott' Gomberg's method becomes uncertain under similar conditions.

In the experiments just quoted ten extractions with chloroform yielded but 34.85 per cent. of the total caffein, or on an average each treatment removed only 3.485 per cent., while the three subsequent treatments removed an additional 13.33 per cent. of the whole, or 4.44 per cent. for each extraction, $i$. e., although the total substance in solution had been decreased by more than one third the average amount given up to chloroform increased in the IIth, I 2 th and I 3 th treatment; while in the 14th, I5th and 16 th but 1.735 per cent., or on an average of $0.57^{8}$ per cent. for each shaking was obtained.

Although the writer had never attempted a caffein determination under the conditions mentioned, he was, from theoretical considerations, inclined to question the figures given, and accordingly made the following experiments.

1 Proceedings Am. Pharm. Ass., 1896. 
I.0137 gram caffein, rendered anhydrous by keeping in a desiccator over sulphuric acid until its weight remained constant, was dissolved in sixty cc. ten per cent. sulphuric acid and shaken successively with nine portions of chloroform, twentyfive $c c$. each; the chloroform solutions evaporated at a gentle heat and the residue dried over sulphuric acid to constant weight.

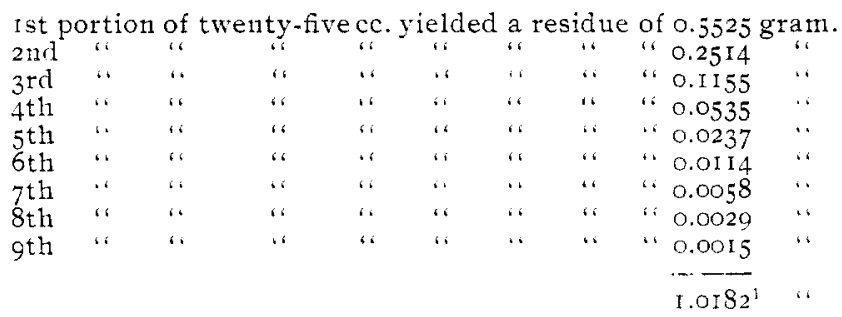

In the second experiment I.000 gram anhydrous caffein in sixty cc. ten per cent. sulphuric acid, extracted as before, with chloroform in proportions of twenty-five cc. each :

Ist, $2 \mathrm{~d}$ and $3 \mathrm{rd}$ portions gave a total residue of $0.9086 \mathrm{gram}$.

4 th, 5 th and 6 th

7 th, 8 th and 9 th

" $\frac{0.0854}{0.0134}$ I.0074 ".

The sulphuric acid used in Gomberg's experiments was designated as " ( $I:$ IO) " by which it is presumed an acid containing ten per cent. by weight of sulphuric acid was meant; since, however, it was possible that sulphuric acid I: Io by volume was the strength of the acid used, a determination was made with an acid with such concentration, $i . e$., ten cc. concentrated sulphuric acid mixed with water enough to make when cold, I00 cc. In sixty cc. of this were dissolved 0.9790 gram caffein and extracted with chloroform in portions of twenty-five cc. each as before.

rst, 2 nd and 3 rd portion yielded a total residue of 0.6484 gram.

4 th, 5 th and 6 th

7 th, 8th and 9 th

Ioth, IIth, I2th, I3th, r4th, I5th and I6th

" 0.2222 " 0.0756

1 No explanation is offered to account for the plus error in the above. Contamination with sulphuric acid was suspected, but disproved. 
As was to be expected, this confirms in a general way, the statement relative the difficulty with which caffein is shaken out of solutions containing a large proportion of sulphuric acid; in no way, however, does it agree with the data given by Gomberg, who by ten successive treatments with chloroform removed only 34.85 per cent., while my figures show that when a ten per cent. sulphuric acid was used, with but three extractions, fully ninety per cent. was recorered, and even with a still stronger acid ( +9 by volume), three portions of chloroform removed about sixty-five per cent.

UNIVERSITY of IllinoIs. SChoOL OF PHARMacs:

\section{CONTRIBUTION TO THE KNOWLEDGE OF THE RUTHENOCYANIDES.}

BY JAS. I,EWIS HOWE.

Recelved August 27, 1896.

POTASSIUM ruthenocyanide was described by Claus, in I 854 , in his "Beiträge zur Chemie der Platinmetalle." The salt was formed by fusing ammonium rutheninitrosochloride $^{1}$ (tetrachloride of Claus) with potassium cyanide. The attempt was also made to form it by fusing potassium ferrocyanide with ruthenium, but it was found impossible to separate the ferrocyanide and ruthenocyanide. It is probable that some of Claus' experiments were carried out with a ruthenocyanide contaminated with ferrocyanide, from the fact that he describes copper ruthenocyanide as brown, whereas, when free from the ferrocyanide, it is pale green. Potassium ruthenocyanide in reactions and crystallization resembles very closely the ferrocyanide, except that when pure it is white. Its crystallography as well as that of the isomorphous ferrocyanide and osmocyanide are described by $\mathrm{A}$. Dufet. ${ }^{2}$

Preparation of potassium ruthenocyanide for the purpose of carrying out experiments upon it not yet completed, gave occasion to the work recorded in this paper.

In the Claus method of preparation, a large proportion of the ammonium rutheninitrosochloride is decomposed with separation of metallic ruthenium, and while a part of the ruthenocya-

1 Joly : Compt. rend.. 108, 854, 7889 ; Howe : J. Am. Chem. Soc., 16, 388, 1894.

2 Compt. rend., (1895), 120, 377. 